\title{
A CASE OF ALTERED SENSORIUM WITH MOVEMENT DISORDER
}

\author{
N. M. Basith Ahamed ${ }^{1}$, Senthi N², Santhosh Kumar P3
}

1 Junior Resident, Department of General Medicine, Sri Ramachandra Medical College, Porur.

2Professor, Department of General Medicine, Sri Ramachandra Medical College, Porur.

3Junior Resident, Department of General Medicine, Sri Ramachandra Medical College, Porur.

HOW TO CITE THIS ARTICLE: Ahamed NMB, Senthi N, Kumar SP. A case of altered sensorium with movement disorder. J. Evolution Med. Dent. Sci. 2017;6(92):6658-6659, DOI: 10.14260/jemds/2017/1442

\section{PRESENTATION OF CASE}

Hemichorea generally occurs due to stroke, neoplasm or granuloma in the contralateral basal ganglia.(1) Metabolic derangements especially hyperglycaemia can also cause focal neurological dysfunction like hemiparesis, focal seizure.(2,3) Recently there have been case reports of hemichorea reported due to nonketotic hyperglycaemia with characteristic MRI findings predominantly in the Asian population.(4) This case is being presented to highlight the aspects pertaining to the clinical and neuroradiological diagnosis of hemichorea associated with nonketotic hyperglycaemia.

A 65-year-old female who is a known case of type 2 diabetes mellitus, chronic kidney disease, systemic hypertension with history of involuntary movements of right side, first involving the upper limb and then followed by homolateral lower limb. She was on oral hypoglycaemic drugs for 6 years, and also had history of altered sensorium for 6 hours. There was no other relevant history.

\section{On Examination}

She was conscious, disoriented and had a GCS -12 . Her vitals were stable. She had continuous, violent, flinging involuntary movements of the right upper and lower extremities that persisted but significantly reduced during sleep. She did not have any local neurological deficits.

\section{Investigations}

Haematological parameters were all normal, blood sugar was $623 \mathrm{mg} / \mathrm{dL}$, but urinary ketone bodies were absent. Serum osmolality was $328 \mathrm{mOsm} / \mathrm{L}$. ABG was normal. Serum creatinine was 1.8. Serum electrolytes were within normal limits. ECG and chest x-ray were normal. Liver function tests were normal. 2D-Echo was normal.

\section{CSF Analysis}

There were no cells, proteins, and sugars were within normal limits. EEG was also normal.

\section{Imaging}

CT brain showed normal study. MRI brain showed chronic infarct with gliosis seen involving the left frontal lobe adjacent to the frontal horn of the left lateral ventricle, small vessel ischaemic changes I (Figure 1).

'Financial or Other Competing Interest': None.

Submission 02-11-2017, Peer Review 17-11-2017,

Acceptance 23-11-2017, Published 04-12-2017.

Corresponding Author:

Dr. N. M. Basith Ahamed,

30/9, Venkatasamy Street,

Santhome, Chennai-600004.

E-mail: basithhhh@gmail.com

DOI: $10.14260 /$ jemds $/ 2017 / 1422$

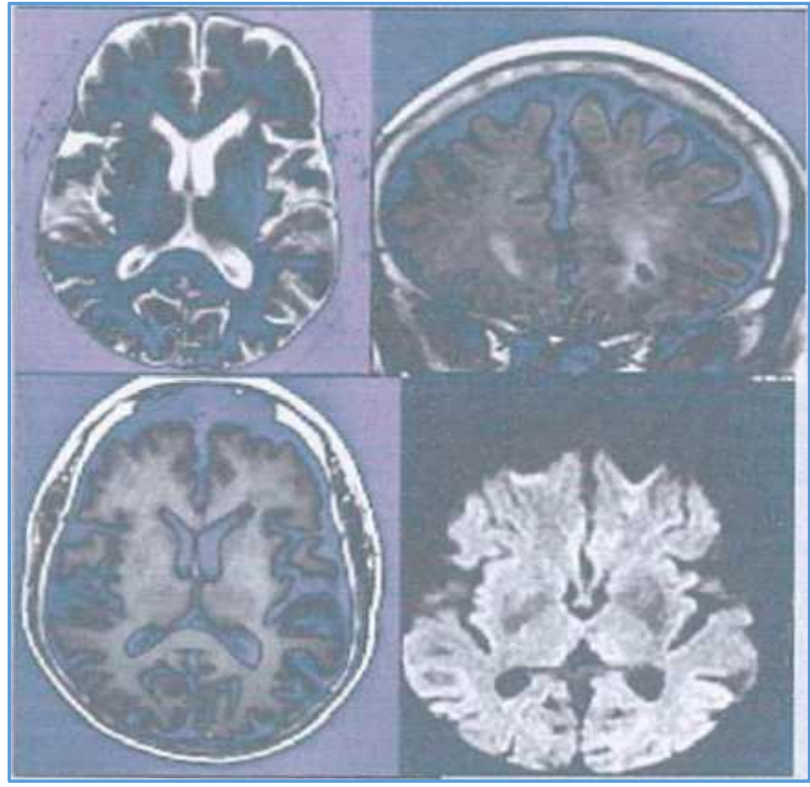

Figure 1

\section{CLINICAL DIAGNOSIS AND DISCUSSION OF MANAGEMENT}

With high blood sugars and urine ketone bodies absent and a clinical picture of choreiform movements and also altered sensorium, a diagnosis of Hemichorea-hemiballismus secondary to hyperglycaemia was made. Her blood sugars were controlled with insulin. She was put on medications for her involuntary movements, clonazepam and carbamazepine. She was also given antiplatelets, antihypertensives, and other supportive measures. Neurologist opinion was sought and seizure disorder was ruled out by performing EEG. Patient had delayed recovery and her sensorium and involuntary movements improved after 3 weeks.

\section{PATHOLOGICAL DISCUSSION}

Hemichorea-hemiballismus (HCHB) is a characteristic relatively benign disorder affecting the elderly and may often be the presenting manifestation of hyperglycaemia. In our patient, in spite of correcting all the metabolic parameters, the patient had persistent choreiform movements and altered sensorium, which was not explained by the imaging findings as well. The usual findings in a patient with nonketotic hyperosmolar state induced hemichorea in MRI is T1W1 hyperintensities over the caudate nucleus. But this imaging finding was not present in our patient. Also, our patient had persistent altered sensorium and choreiform movements in spite of correcting all metabolic parameters. MRI showed small vessel ischaemic changes and chronic Infarct over the left frontal lobe which did not explain the altered sensorium as well. CT also showed normal study. 
In our patient, the delirium and hemichorea persisted for longer duration of time and also, we are highlighting this case to stress on the fact that diabetic nonketotic hyperosmolar state induced hemichorea in elderly may present atypically without characteristic finding in imaging like T1W1 hyperintensities in caudate nucleus, also the choreiform movements might take a longer time to recover. It is also essential to rule out other causes for persistent altered sensorium and involuntary movements such as structural and organic causes in elderly which was ruled out in this patient.

\section{CONCLUSION}

In an elderly female, diabetic nonketotic hyperosmolar state causing hemichorea may present atypically and it also might take a long time for recovery. It is essential to rule out other organic and structural conditions causing altered sensorium, and choreiform movements in a patient with nonketotic hyperosmolar state.

\section{REFERENCES}

[1] Dewey RB, Jankovic J. Hemiballismus-hemichorea. Clinical and pharmacologic findings in 21 patients. Arch Neurol 1989;46(8):862-7.

[2] Maccario M. Neurological dysfunction associated with nonketotic hyperglycemia. Arch Neurol 1968;19(5):525-34.

[3] Grant C, Warlow C. Focal epilepsy in diabetic nonketotic hyperglycaemia. $\mathrm{Br}$ Med J (Clin Res Ed) 1985;290(6476):1204-5.

[4] Oh SH, Lee KY, Im JH, et al. Chorea associated with non-ketotic hyperglycemia and hyperintensity basal ganglia lesion on T1-weighted brain MRI study: a meta-analysis of 53 cases including four present cases. J Neurol Sci 2002;200(1-2):57-62. 